\title{
Magneto-hydrodynamics (MHD) Bioconvection Nanofluid Slip Flow over a Stretching Sheet with Thermophoresis, Viscous Dissipation and Brownian Motion
}

\author{
Falana Ayodeji", Alegbeleye Tope, Olabanji Pele \\ Department of Mechanical Engineering, University of Ibadan, Ibadan, Nigeria \\ Email address: \\ falanaayode@gmail.com (F. Ayodeji), topealegbeleye@yahoo.com (A. Tope), peleolabanji@gmail.com (O. Pele) \\ ${ }^{*}$ Corresponding author
}

\section{To cite this article:}

Falana Ayodeji, Alegbeleye Tope. Magneto-hydrodynamics (MHD) Bioconvection Nanofluid Slip Flow over a Stretching Sheet with Thermophoresis, Viscous Dissipation and Brownian motion. Machine Learning Research. Vol. 4, No. 4, 2019, pp. 51-60. doi: $10.11648 /$ j.mlr.20190404.12

Received: July 6, 2019; Accepted: August 18, 2019; Published: January 8, 2020

\begin{abstract}
The bioconvection Magneto-Hydrodynamics (MHD) flow of nanofluid over a stretching sheet with velocity slip and viscous dissipation is studied. The governing nonlinear partial differential equations of the flow are transformed into a system of coupled nonlinear ordinary differential equations using similarity transformation. These coupled ordinary differential equations are solved using fourth order Runge Kutta-Fehlberg integration method along with shooting technique. Solutions showing the effects of pertinent parameters on the velocity temperature, nanoparticles concentration, skin friction, Nusselt number and microorganism density are illustrated graphically and discussed. It is observed that there is enhancement of the motile microorganism density as thermal slip and Eckert number increase but microorganism density slip parameter have the opposite effect on the microorganism density. It is also found that an increase in Lewis number results in reduction of the volume fraction of nanoparticles and concentration boundary-layer thickness. Brownian motion, $\mathrm{Nb}$ and Eckert number, Ec decrease both local Nusselt number and local motile microorganism density but increases local Sherwood number. In addition, as the values of radiation parameter $\mathrm{R}$ increase, the thermal boundary layer thickness increases. Finally, thermophoresis parameter, Nt decreases both local Sherwood number, local Nuseselt number and local motile microorganism density. Comparisons of the present result with the previously published results show good agreement.
\end{abstract}

Keywords: MHD Flow, Thermophoresis, Viscous Dissipation, Brownian Motion Slip Conditions, Nano Fluid, Heat and Mass Transfer

\section{Introduction}

The concept of boundary layer flow over a stretching sheet has many applications in mechanical, chemical engineering, etc. Quite a number of researches [1-4] have focused on flow on a stretching sheet with different properties in the presence of additional effects. The flow and heat transfer characteristics over a stretching sheet have important industrial applications, for instance, in the aerodynamic extrusion of polymer sheet from a die, in metallurgy, cooling of an infinite metallic plate in a cooling bath, cooling or drying of papers and in textile and glass fiber production. Many subsequent studies also appeared examining heat and mass transfer in stretching boundary layer flows which includes Sreedevi et al, Shafiq et al. and Togun et al. [5-7] Recently nanofluid stretching boundary layer flows have also been considered with representative works of Uddin et al., Rana and Bhargava, Nadeem et al., and Rana et al. [8-11] among others. In the manufacturing of such sheets, the melt issuing from a slit is subsequently stretched. The rates of stretching and cooling have a significant influence on the quality of the final product with desired characteristics. The aforementioned processes involve cooling of a molten liquid by drawing into a cooling system. The properties desired for the product of such process usually depend on two characteristics which are the cooling liquid used and the rate of stretching. Liquids of non-Newtonian characteristics with weak electrical conductivity can be chosen as a cooling 
liquid as their flow and the heat transfer rate can be regulated through some external means.

Furthermore, the MHD fluid flow and heat transfer over a surface which stretches linearly or nonlinearly have been extensive studied because of its several practical applications in different chemical and mechanical industries. After the pioneering work of Sakiadis [12] a large number of research papers on a stretching sheet have been published by considering various governing parameters such as suction/injection, porosity, magnetic field parameter, and radiation with different types of fluids such as Newtonian, non-Newtonian, micropolar, and couple stress fluids. However, more literatures show that boundary layer flow over a stretching plate is within the scope of Newtonian and non-Newtonian fluids flow with no slip boundary condition. In addition to the past work, Nazar et al. [13] studied the unsteady boundary-layer flow of a nanofluid over a stretching sheet caused by an impulsive motion or a suddenly stretched surface using the Keller-box method. Abel et al and Bakier A. Y [14-15] investigated the Effects of non-uniform heat source on viscoelastic fluid flow and heat transfer over a stretching sheet. Makinde et al [16] studied the effect of buoyancy force on MHD flow and heat transfer of a nanofluid past a convectively heated stretching/shrinking sheet and they found that both the skin friction and the local Sherwood number decrease while the local Nusselt number increases with increasing buoyancy force. In addition, the theory of bio-thermal convection due to temperature gradient and swimming of the microorganisms was introduced by Kuznetsov [17] and verified that the bioconvection parameters influence mass, heat, and motile microorganism transport rates.

In this study, our objective is to investigate the effect of thermophoresis and Brownian motion on the rate of heat transfer of a nanofluid over a stretching sheet with temperature and velocity slip.

\section{Mathematical Formulation}

Consider a two-dimensional steady boundary layer flow of a nanofluid over a stretching sheet with surface temperature $\mathrm{T}_{\mathrm{w}}$ and concentration $\mathrm{C}_{\mathrm{w}}$. The stretching velocity of the sheet is $\mathrm{u}_{\mathrm{w}}=\mathrm{ax}$, with a, being a constant. Let the wall mass transfer be $\mathrm{V}_{\mathrm{w}}$. The flow is assumed to be generated by stretching sheet issuing from a thin slit at the origin. The sheet is then stretched in such a way that the speed at any point on the sheet becomes proportional to the distance from the origin. The ambient temperature and concentration are $\mathrm{T}_{\infty}$ and $\mathrm{C}_{\infty}$ respectively. The flow is subjected to the combined effects of thermal radiation $\mathrm{R}$ and a transverse magnetic field of strength $\mathrm{B}_{0}$, which is assumed to be applied in the positive $\mathrm{y}$ direction.

It is assumed that the induced magnetic field, the external electric field and the electric field due to the polarization of charges are negligible. Using the bosea boundary layer approximations, the governing equations can be written thus:

$$
\begin{gathered}
\frac{\partial u}{\partial x}+\frac{\partial v}{\partial y}=0 \\
\mathrm{u} \frac{\partial u}{\partial x}+\mathrm{v} \frac{\partial u}{\partial y}=-\frac{1}{\rho} \frac{\partial p}{\partial x}+\mathrm{v}\left(\frac{\partial^{2} u}{\partial x^{2}}+\frac{\partial^{2} u}{\partial y^{2}}\right)-\frac{\sigma B_{o}^{2} u}{\rho} \\
\mathrm{u} \frac{\partial v}{\partial x}+\mathrm{v} \frac{\partial v}{\partial y}=-\frac{1}{\rho} \frac{\partial p}{\partial y}+\mathrm{v}\left(\frac{\partial^{2} v}{\partial x^{2}}+\frac{\partial^{2} v}{\partial y^{2}}\right)-\frac{\sigma B_{o}^{2} v}{\rho} \\
\mathrm{u} \frac{\partial T}{\partial x}+\mathrm{v} \frac{\partial T}{\partial y}=\alpha\left(\frac{\partial^{2} T}{\partial x^{2}}+\frac{\partial^{2} T}{\partial y^{2}}\right)-\frac{1}{\rho c_{p}}\left(\frac{\partial q_{r}}{\partial y}\right)+\tau\left\{D_{b}\left(\frac{\partial C}{\partial x} \frac{\partial T}{\partial x}+\frac{\partial C}{\partial y} \frac{\partial T}{\partial y}\right)\right. \\
+\frac{D_{t}}{T_{\infty}}\left[\left(\frac{\partial T}{\partial x}\right)^{2}+\left(\frac{\partial T}{\partial y}\right)^{2}\right]+\frac{\mathrm{v}}{c_{p}}\left(\frac{\partial u}{\partial y}\right)^{2}+\frac{\sigma B_{0}^{2}}{\rho} \mathrm{u}^{2} \\
\mathrm{u} \frac{\partial n}{\partial x}+\mathrm{v} \frac{\partial C}{\partial y}=\mathrm{Db}\left(\frac{\partial^{2} C}{\partial x^{2}}+\frac{\partial^{2} C}{\partial y^{2}}\right)+\frac{D_{t}}{T_{\infty}}\left(\frac{\partial^{2} T}{\partial x^{2}}+\frac{\partial^{2} T}{\partial y^{2}}\right) \\
+\frac{b W_{C}}{C_{\omega-C_{\infty}}}\left[\frac{\partial}{\partial y}\left(\mathrm{n} \frac{\partial C}{\partial y}\right)+\frac{\partial}{\partial x}\left(\mathrm{n} \frac{\partial C}{\partial x}\right)\right]=\mathrm{D}_{\mathrm{n}}\left(\frac{\partial^{2} n}{\partial x^{2}}+\frac{\partial^{2} n}{\partial y^{2}}+2 \frac{\partial^{2} n}{\partial x \partial y}\right)
\end{gathered}
$$

In the above expressions $\mathrm{u}$ and $\mathrm{v}$ are the nanofluid velocity components, $\mathrm{T}$ is the temperature, $\mathrm{n}$ is the density of motile microorganisms, $\mathrm{p} \rho, \sigma, \mathrm{B}_{0}, \mathrm{D}_{\mathrm{b}}, \mathrm{D}_{\mathrm{t}}$ and $\mathrm{D}_{\mathrm{n}}$ are the fluid pressure, the density of the base fluid, electrical conductivity, magnetic field, the Brownian diffusion, thermophoresis diffusion coefficient and the diffusivity of microorganisms respectively.

The given boundary conditions are:

$$
\text { At } y=0, u=u_{w}+L \frac{\partial u}{\partial y}, v=V_{m}
$$

$$
\begin{gathered}
T=T_{w}+\delta \frac{\partial T}{\partial y}, C=C_{w}+\varepsilon \frac{\partial C}{\partial y} \text { and } \\
n=n_{w}+\zeta \frac{\partial n}{\partial y} \\
n \rightarrow n_{\infty} \text { as } \mathrm{y} \rightarrow \infty \\
\mathrm{u} \rightarrow U_{\infty}=0, \mathrm{~T} \rightarrow T_{\infty}, \mathrm{C} \rightarrow C_{\infty}
\end{gathered}
$$




$$
\mathrm{C}_{\mathrm{w}}=C_{\infty}+C\left(\frac{x}{l}\right)^{2}, \mathrm{n}_{\mathrm{w}}=n_{\infty}+D\left(\frac{x}{l}\right)^{2}
$$

Where $\mathrm{L}, \delta, \varepsilon$ and $\zeta$ are the velocity, the thermal, concentration and density slip factors respectively, and when

$\mathrm{L}=\delta=\varepsilon=\zeta=0$, the no-slip condition is recovered, $l$ is the reference length of the sheet. The above boundary condition is valid when $\mathrm{x}<<l$ which occurs very near to the slit.

We introduce similarity functions as:

$$
\begin{gathered}
\eta=y \sqrt{\frac{a}{v}} \\
\psi=\sqrt{\mathrm{a} v} x f(\eta) \\
\mathrm{u}=\frac{\partial \psi}{\partial y}, \mathrm{v}=-\frac{\partial \psi}{\partial x} \\
\mathrm{u}=\mathrm{a} x f^{\prime}(\eta), \mathrm{v}=-\sqrt{\mathrm{a} v} f(\eta) \\
\theta(\eta)=\frac{T-T_{\infty}}{T_{w-T_{\infty}}}, \phi(\eta)=\frac{c-C_{\infty}}{C_{w-C_{\infty}}}
\end{gathered}
$$

Where $\psi$ is the stream function, the continuity equation is satisfied if a stream function $\psi(\mathrm{u}, \mathrm{v})$ is chosen as

$$
\mathrm{u}=\frac{\partial \psi}{\partial y}, \mathrm{v}=-\frac{\partial \psi}{\partial x}
$$

The radiative heat flux $\mathrm{q}_{\mathrm{r}}$ is given by

$$
q_{r}=-4 \frac{\sigma}{3 K^{*}} \frac{\partial T^{4}}{\partial y^{4}}
$$

Where $\sigma^{*}$ and $\mathrm{K}^{*}$ are the Stefan-Boltzmann constant and the mean absorption coefficient, respectively. We assume that the temperature difference with in the flow is sufficiently small such that the term $\mathrm{T}^{4}$ may be expressed as a linear function of temperature. This is done by expanding $\mathrm{T}^{4}$ in a Taylor series about a free stream temperature $T_{\infty}$ as follows:

$$
\mathrm{T}=T_{\infty}^{4}+4 T_{\infty}^{3}\left(\mathrm{~T}-T_{\infty}^{4}\right)+6 T_{\infty}^{2}\left(\mathrm{~T}-T_{\infty}^{4}\right) 2+\ldots
$$

If we neglect higher-order terms in the above Eq. (14) beyond the first order in $\left(\mathrm{T}-T_{\infty}\right)$, we have:

$$
\mathrm{T} 4 \cong 4 T_{\infty}^{3}-3 T_{\infty}^{4}
$$

Thus, substituting Eq. (15) into Eq. (13), we have:

$$
q_{r}=-\frac{16 T_{\infty}^{3} \sigma^{*}}{3 K^{*}} \frac{\partial T}{\partial y}
$$

The transformed governing conservation equations and boundary conditions are then obtained as,

$$
\begin{gathered}
f^{\prime \prime \prime}+f f^{\prime \prime}-\left(f^{2}\right)-\mathrm{M} f^{\prime}=0 \\
\left(1+\frac{4}{3} R\right) \theta^{\prime \prime}+\operatorname{Pr} f \theta^{\prime}+\operatorname{PrEc} f^{\prime \prime 2}+\operatorname{PrMEc} f^{2}+ \\
\operatorname{Pr} N_{b} \theta^{\prime} \phi^{\prime}+\operatorname{Pr} N_{t} \theta^{2}=0 \\
\phi^{\prime \prime}+\operatorname{Lef} \phi^{\prime}+\frac{N_{t}}{N_{b}} \theta^{\prime \prime}=0 \\
\chi^{\prime \prime}+\mathrm{L}_{\mathrm{b}} f \chi^{\prime}-P_{e}\left[\phi^{\prime \prime}(\Omega+\chi)+\chi^{\prime} \phi^{\prime}\right]=0
\end{gathered}
$$

as $\eta \rightarrow 0$.

$$
\begin{gathered}
f(0)=\lambda, f^{\prime}(0)=1+\xi f^{\prime \prime}(0), \\
\theta(0)=1+\beta \theta^{\prime}(0), \phi(0)=1+\gamma \phi^{\prime}(0), \\
\chi(0)=1+\varphi \chi^{\prime}(0) \\
\text { As } \eta \rightarrow \infty \\
f^{\prime}(\infty)=0, \theta(\infty)=0, \phi(\infty)=0, \chi(\infty)=0
\end{gathered}
$$

Where the primes denote differentiation with respect to $\eta$ and the parameter appearing in eqs. (17-20) are defined as:

$$
\begin{gathered}
\operatorname{Pr}=\frac{v}{\alpha}, L e=\frac{v}{D_{b}}, \mathrm{Lb}=\frac{v}{D_{m}} \text { pe }=\frac{b w_{c}}{D_{m}}, \Omega=\frac{n_{\infty}}{n_{w-} n_{\infty}}, N_{b} \\
=\frac{\tau\left(C_{w-} C_{\infty}\right) D_{b}}{\mathrm{~V}}, N_{t}=\frac{\tau\left(T_{w-} T_{\infty}\right) D_{t}}{\mathrm{v} T_{\infty}}, \\
E c=\frac{\left(u_{w}\right)^{2}}{c_{p}\left(T_{w}-T_{\infty}\right),} \mathrm{R}=\frac{4 T_{\infty}^{3} \sigma^{*}}{3 K^{*} K}, \mathrm{M}=\frac{\sigma B_{o}^{2}}{\rho a} \\
\xi=L \sqrt{\frac{a}{v}}, \beta=\delta \sqrt{\frac{a}{v}}, \gamma=\varepsilon \sqrt{\frac{a}{v}}, \varphi=\zeta \sqrt{\frac{a}{v}}
\end{gathered}
$$

In Eq. (17-21), Pr, Le, $\mathrm{L}_{\mathrm{b}}, \Omega, \mathrm{N}_{\mathrm{b}}, \mathrm{N}_{\mathrm{t}}, \mathrm{Pe}, \mathrm{Ec}, \mathrm{R}, \mathrm{M}, \xi$, $\beta, \gamma$ and $\varphi$ represent Prandtl number, Lewis number, Bioconvection Lewis number, Bioconvection concentration difference parameter, Brownian motion parameter, thermophoresis parameter, Bioconvection Péclet number, Eckert number, thermal radiation, Magnetic parameter, Velocity slip parameter, Thermal slip parameter, Concentration slip parameter and density slip parameter respectively

The quantities of practical interest in this study are the local skin friction coefficient (dimensionless wall shear stress) and the local Nusselt number (rate of heat transfer), the local Sherwood number (rate of mass transfer) and the local density number of the motile microorganisms which are defined as:

$$
\mathrm{C}_{\mathrm{f}}=\frac{\tau_{w}}{\rho_{f} u_{0}^{2}}, \mathrm{Nu}_{\mathrm{x}}=\frac{q_{w} x}{k\left(T_{w}-T_{\infty}\right)}, \mathrm{Sh}_{\mathrm{x}}=\frac{q_{m} x}{D_{b}\left(T_{w}-T_{\infty}\right)}, \mathrm{Nn}_{\mathrm{x}}=\frac{x q_{n}}{D_{n}\left(n_{w}-n_{\infty}\right)}
$$

Where the heat flux $\mathrm{q}_{\mathrm{w}}$ and mass flux $\mathrm{h}_{\mathrm{m}}$ are given as:

$$
\mathrm{q}_{\mathrm{w}}=-\mathrm{k}\left(\frac{\partial T}{\partial y}\right) \mathrm{y}=0, \mathrm{~h}_{\mathrm{m}}=-\mathrm{D}_{\mathrm{b}}\left(\frac{\partial C}{\partial y}\right) \mathrm{y}=0
$$

Using Eqs. (22) and (23)

$$
\begin{aligned}
& \mathrm{C}_{\mathrm{fx}}=\left(R e_{x}\right)^{-\frac{1}{2}} \mathrm{C}_{\mathrm{f}=}-f^{\prime \prime}(0), N u_{x}=\left(R e_{x}\right)^{-\frac{1}{2}} \mathrm{Nu}=-\theta^{\prime}(0) \text {, } \\
& S h_{x}=\left(R e_{x}\right)^{-\frac{1}{2}} \mathrm{Sh}=-\phi^{\prime}(0) \\
& N n_{x}=\left(R e_{x}\right)^{-\frac{1}{2}} \mathrm{Nn}=-\chi^{\prime}(0)
\end{aligned}
$$

\section{Numerical Solution of the Governing Equation}

The governing equations with the associated boundary 
conditions equations. (17) - (20) are numerically integrated using the fourth order Runge-Kutta method and a shooting technique with Matlab package. Firstly, they were converted into initial value differential equations using shooting technique and Runge-Kutta method to solve first order differential equations. We assumed the unspecified initial conditions for unknown variables, the transformed first order differential equations are integrated numerically as an initial valued problem until the given boundary conditions are satisfied. We define new variables as:

$$
\begin{aligned}
& f_{1}=f f_{2}=f^{\prime} f_{3}=f^{\prime \prime} \\
& f_{4}=f_{5}={ }^{\prime} f_{6}=\phi \\
& f_{7}=\emptyset^{\prime} f_{8}=\chi f_{9}=\chi^{\prime \prime}
\end{aligned}
$$

Equations (17)-(20) are then reduced to systems of first order differential equation.

\section{Results and Discussion}

The present work is compared it with the works of Wubshet and Bandari, Anderson and Hayat et al [18-20]. (MHD flow and heat transfer over permeable stretching sheet with slip conditions). The results from this work with regards to good was found to be in agreement with theirs comparison of Results for the skin friction $f^{\prime \prime}(0)$ and reduced Nusselt number $-\theta^{\prime}(0)$ are presented in tables 1 and 2. Numerical values of skin friction coefficient, local Nusselt number, and local Sherwood number and motile microorganism local density are presented in Table 3 against all the pertinent parameters.

Table 1. Comparison of skin friction coefficient $-f^{\prime \prime}(0)$ for different values of $\xi$ when $\lambda=\varphi=0$.

\begin{tabular}{llll}
\hline$\xi$ & Anderson [19] & Haya et al [20] & Present Result \\
\hline 0.0 & 1.0000 & 1.0000 & 0.9998 \\
10 & 0.0812 & 0.081249 & 0.0812 \\
20 & 0.0438 & 0.043782 & 0.0437 \\
50 & 0.0186 & 0.018634 & 0.0186 \\
\hline
\end{tabular}

Table 2. Comparison of local Nusselt number $-\theta^{\prime}(0)$ for different values of $N b$ when $\lambda=M=R=0.5, \xi=\beta=\gamma=1, P r=1, E c=N t=0.2$, Le $=5$.

\begin{tabular}{lllll}
\hline Nb & Le & Nt & Ibrahim and Shanker [18] & Present Result \\
\hline 0.2 & 5 & 0.2 & 0.3980 & 0.3980 \\
0.1 & & 0.4005 & 0.4005 \\
0.3 & & 0.3915 & 0.3911 \\
0.4 & & 0.3884 & 0.3880 \\
0.5 & & 0.4002 & 0.4000 \\
\hline
\end{tabular}

\begin{tabular}{|c|c|c|c|c|c|c|}
\hline Pr & $\mathbf{N t}$ & $\mathrm{Nb}$ & Ec & $-\boldsymbol{\theta}^{\prime}(\mathbf{0})$ & $-\phi 9(0)$ & $-\chi^{\prime}(0)$ \\
\hline 8.0 & 0.2 & 0.2 & 0.2 & 0.9009 & 0.9566 & 0.2544 \\
\hline 10.0 & & & & 0.9480 & 0.9350 & 0.2646 \\
\hline 12.0 & & & & 0.9850 & 0.9178 & 0.2726 \\
\hline 14.0 & & & & 1.0157 & 0.9037 & 0.2789 \\
\hline \multirow[t]{10}{*}{10.0} & 0.1 & & & 1.0103 & 1.0591 & 0.2770 \\
\hline & 0.2 & & & 0.9480 & 0.9350 & 0.2646 \\
\hline & 0.3 & & & 0.8847 & 0.8406 & 0.2514 \\
\hline & 0.5 & & & 0.7600 & 0.7379 & 0.2231 \\
\hline & 0.2 & 0.1 & & 1.0071 & 0.6011 & 0.2797 \\
\hline & & 0.2 & & 0.9480 & 0.9350 & 0.2646 \\
\hline & & 0.3 & & 0.8869 & 1.0468 & 0.2507 \\
\hline & & 0.2 & 0.1 & 1.0150 & 0.9034 & 0.2791 \\
\hline & & & 0.15 & 0.9816 & 0.9191 & 0.2719 \\
\hline & & & 0.2 & 0.9480 & 0.9350 & 0.2646 \\
\hline
\end{tabular}

Table 3. Computation showing the local Nusselt $-\theta^{\prime}(0)$, local Sherwood number $-\phi^{\prime}(0)$ and local microorganisms density number $-\chi^{\prime}(0)$ when $M=1$, $R=0.5$, $\xi=\beta=\gamma=\varphi=0.5, P e=0.2, \Omega=L b=0.1$ for different values of $E c, N t, N b$ and $P r$.

Table 3 presents the variation of the local Nusselt number $\theta(0)$, local Sherwood number $-\phi 9 \quad(0$ and local microorganism density number $-\chi^{\prime}(0)$ with respect to Prandlt number Pr, thermophoresis parameter Nt, Brownian motion parameter $\mathrm{Nb}$ and Eckert number Ec. from this table, as the values Prandlt number increase, the values of local Nusselt number, local Sherwood number local microorganism density number increase. Increase in the value of $\mathrm{Nt}$ leads to decrease in Nusselt number, local Sherwood number and local microorganism density number. As $\mathrm{N}_{\mathrm{b}}$ increases, Nusselt number and local microorganism density number decrease but opposite effect is observed in local Sherwood number. In addition, as the values of Eckert number increase both the values of the local Nusselt number and local microorganism density number decrease but there is increase the local Sherwood number.

In Figures 1-2, it is observed that as $\mathrm{N}_{\mathrm{b}}$ and $\mathrm{N}_{\mathrm{t}}$ increase, the boundary layer thickens and surface temperature increases which results in reduction of heat transfer. Also, as thermal radiation $\mathrm{R}$ increases, the thermal boundary layer thickness increases due to the reduction of rate of heat transfer at the surface, therefore there is increasing surface temperature. 


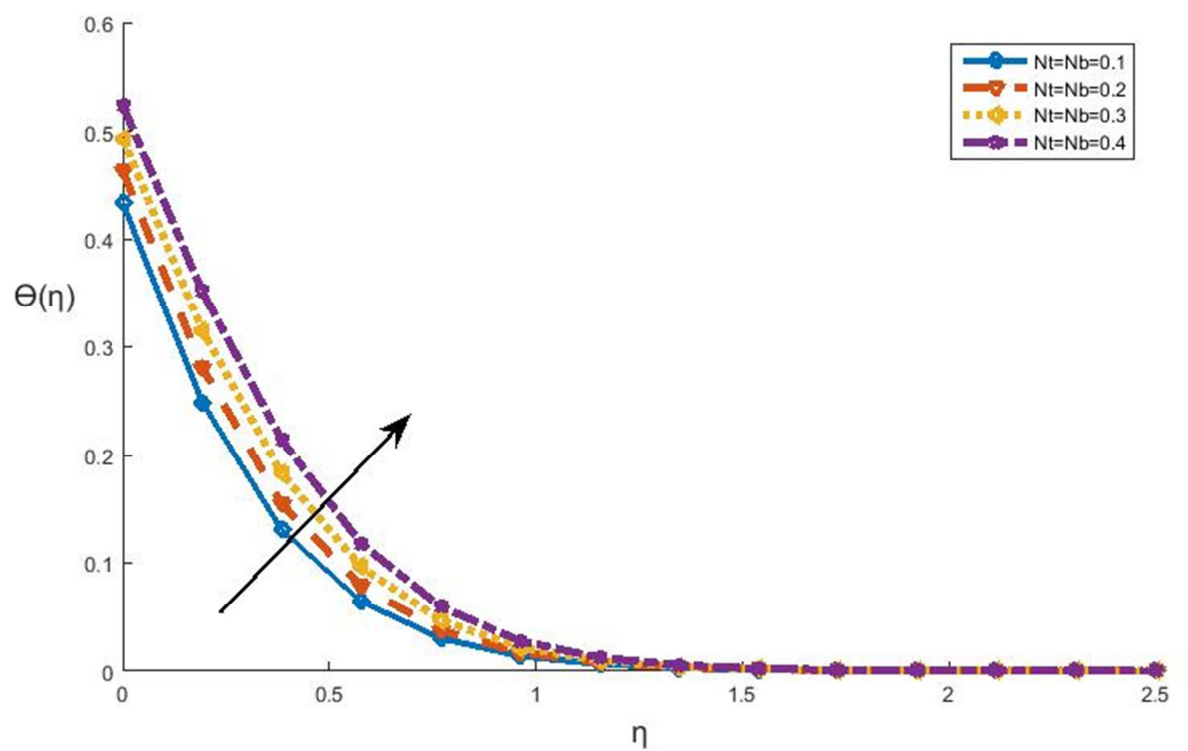

Figure 1. Effect thermophoresis Nt and Brownian motion $\mathrm{Nb}$ on temperature distribution when $E c=0.2, R=0.5, L b=\Omega=0.1, M=1, \xi=\beta=\gamma=0.5, P e=0.2, L e=5$ and $\operatorname{Pr}=10$.

In figure 3 , it is found that the increase in thermophoresis parameter $\mathrm{Nt}$ makes the nanoparticles concentration boundary layer increase. In figure 4 It is also observed that the increase in Brownian motion $\mathrm{Nb}$ makes the nanoparticle concentration profile diminish. This indicates that an increase in thermophoresis parameter induce resistance to the diffusion of mass. Figure 6 illustrates the effect of the prandlt number on the concentration profile. It is found that an increase in prandlt number results in reduction of the volume fraction of nanoparticles and concentration boundary-layer thickness. Figure 6 shows different values of Lewis number. It is found that an increase in Lewis number results in reduction of the volume fraction of nanoparticles and concentration boundary-layer thickness. Also, figure 7, illustrates the variation of radiation on concentration profile. As the values of radiation parameter $\mathrm{R}$ increase, the thermal boundary layer thickness increases. This may be due to the reduction of rate of heat transfer at the surface.

We investigated the bioconvection in nanofluid flow over a stretching sheet surface with microorganism. The effect of various slip parameters on the microorganism concentration of the fluid and other pertinent parameters are shown in Figures 8-11.

In Figures 8-9 we notice that increase in both Eckert number and temperature slip lead to increase in microorganism density in the boundary layer but microorganism density slip parameter have the opposite effect on the microorganism density as shown in Figure 10, $\varphi$ decreases the microorganism concentration in the boundary surface. In figure 11, it is found that the increase in thermal radition parameter increases the motile microorganism profile.

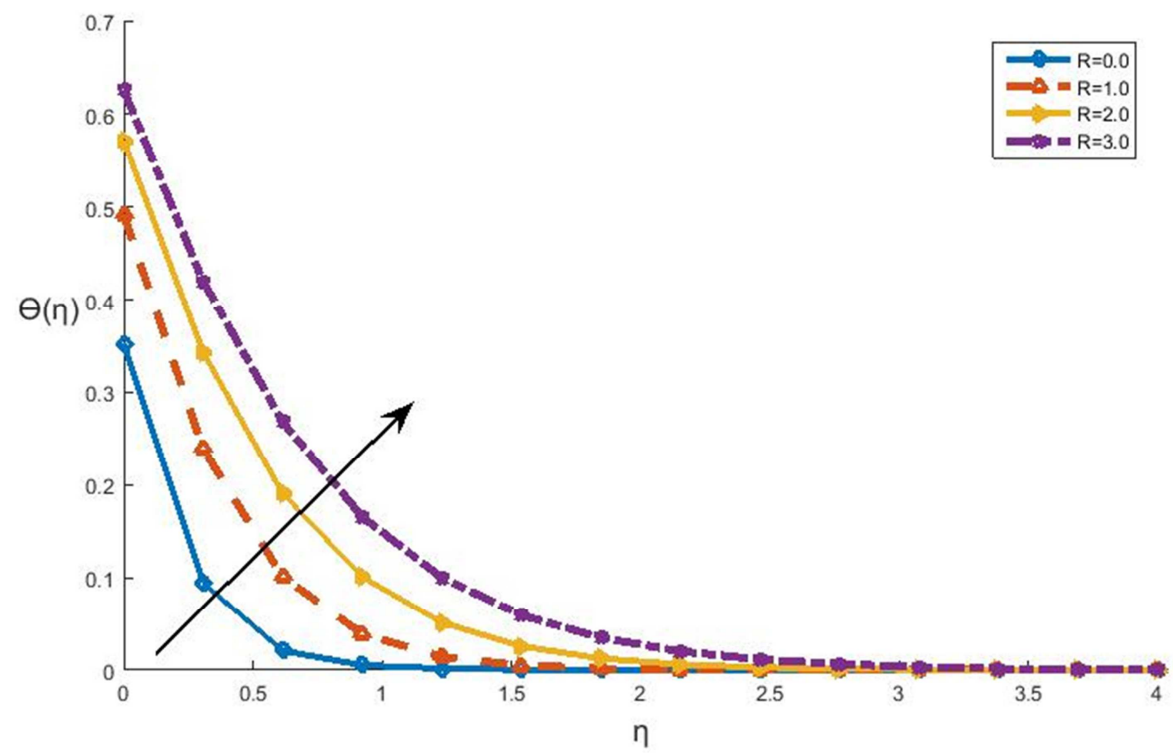

Figure 2. Effect of thermal radiation $R$ on temperature distribution when $N t=N b=E c=0.2, L b=\Omega=0.1, M=1, \xi=\varphi=\gamma=\beta=05, L e=5, P e=0.2$ and $P r=10$. 


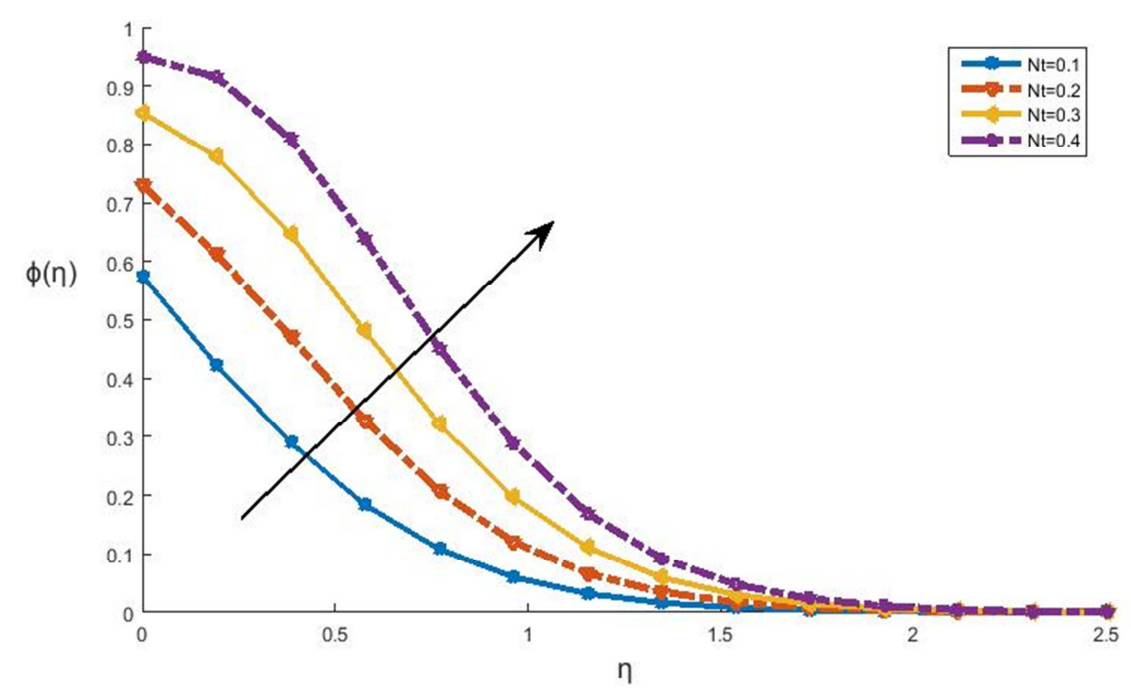

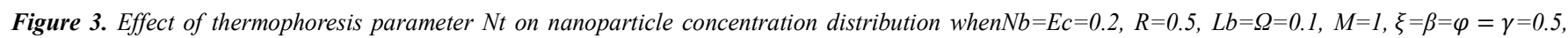
$P e=0.2, L e=5$ and $P r=10$.

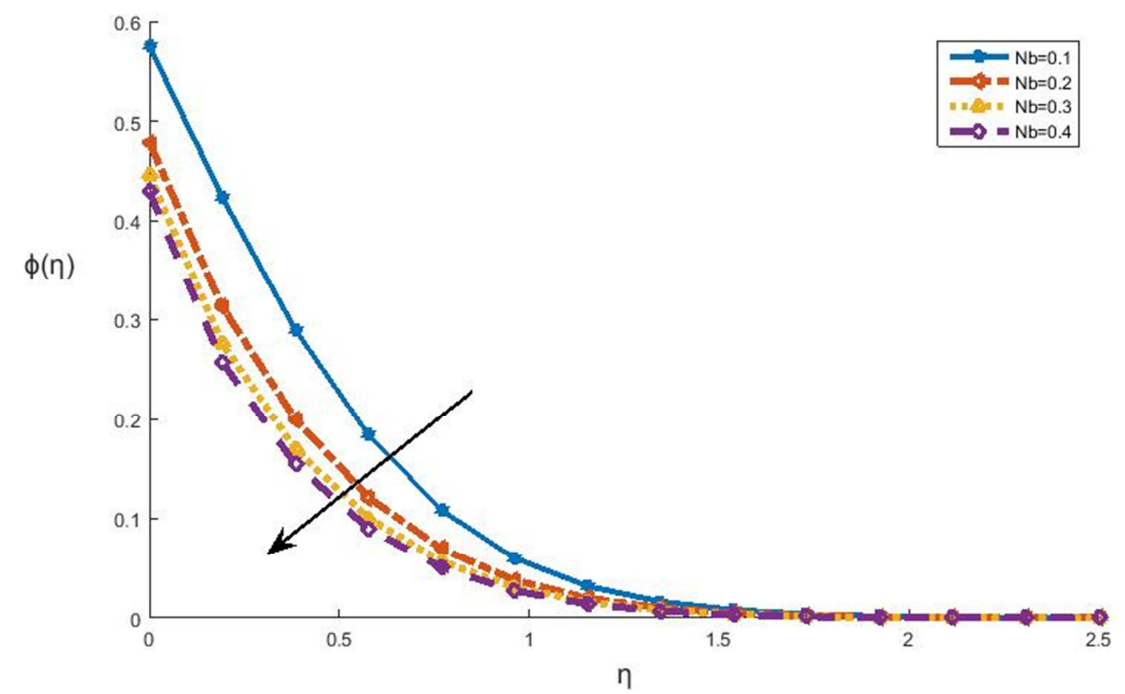

Figure 4. Effect of Brownian motion $N b$ on nanoparticle concentration distribution when $N t=E c=0.2, R=0.5, L b=\Omega=0.1, M=1, \xi=\beta=\varphi=\gamma=0.5, P e=0.2$, $L e=5$ and $P r=10$.

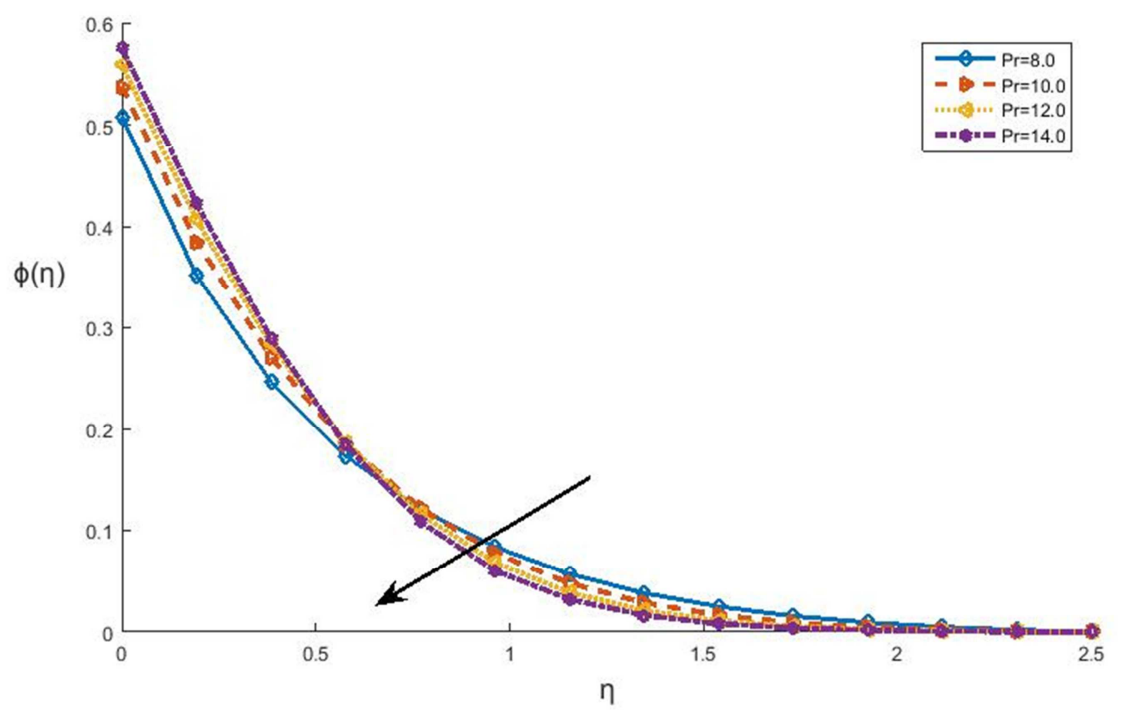

Figure 5. Effect of Prandlt nummber Pr on nanoparticle concentration distribution when $N b=E c=0.2, R=0.5, L b=\Omega=0.1, M=1, \xi=\beta=\varphi=\gamma=0.5, P e=0.2$ and $L e=5$. 


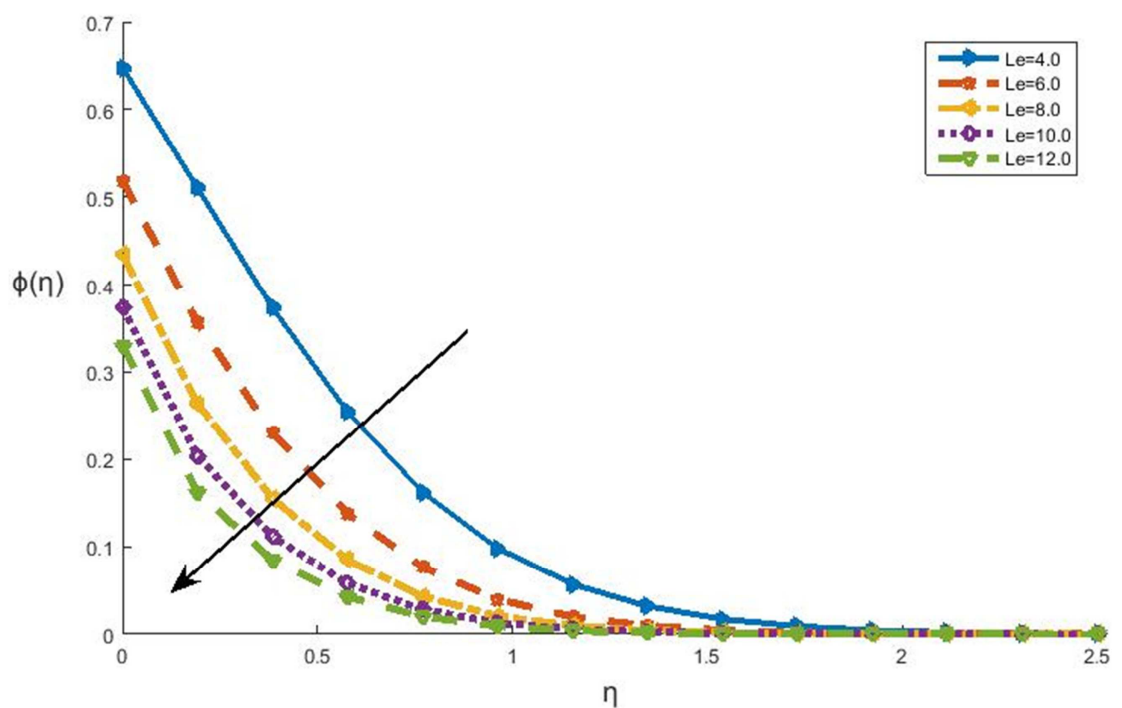

Figure 6. Effect of Lewis number Le on nanoparticle concentration distribution when $N t=N b=E c=0.2, R=0.5, L b=\Omega=0.1, M=1, \xi=\beta=\gamma=\alpha_{1}=0.5, P e=0.2$ and $\operatorname{Pr}=10$.

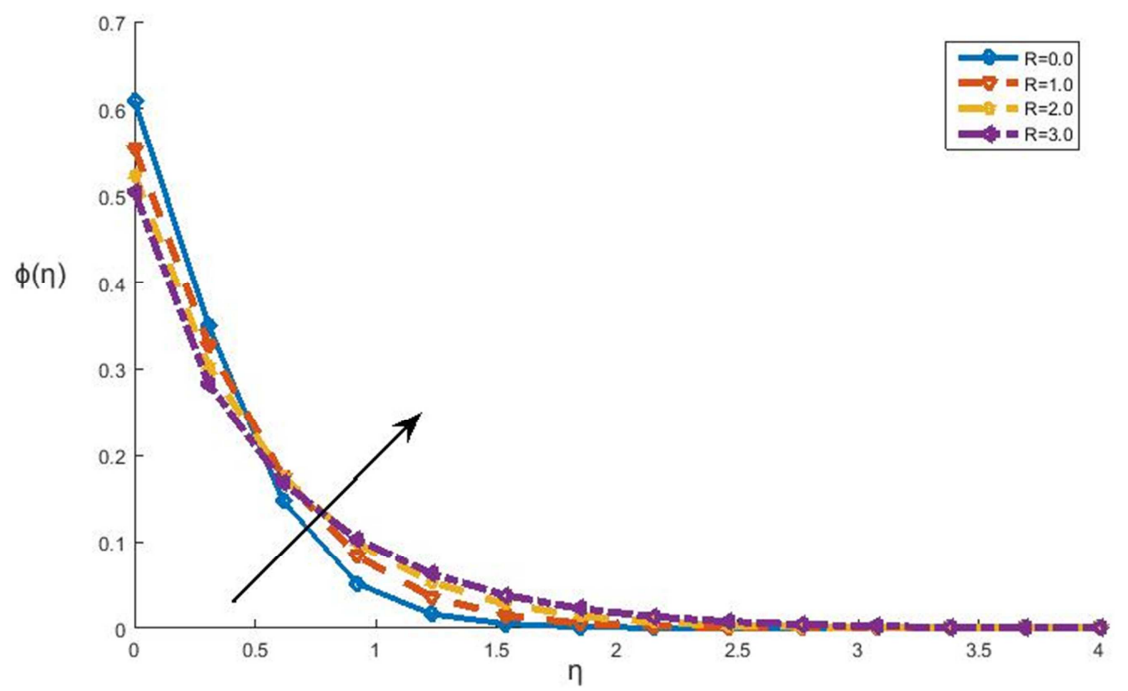

Figure 7. Effect of thermal radiation $R$ on nanoparticle concentration distribution when $N t=N b=E c=0.2, L b=\Omega=0.1, M=1, \xi=\beta=\gamma=\varphi=0.5, P e=0.2, L e=5$ and $\mathrm{Pr}=10$.

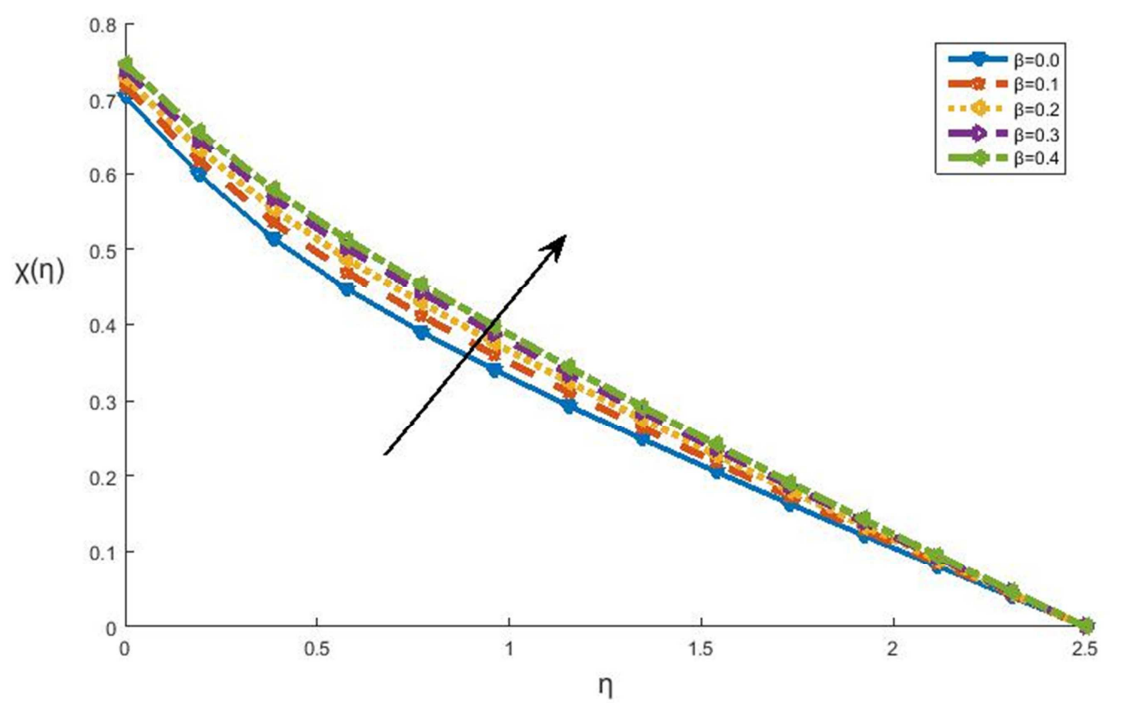

Figure 8. Effect of temperature slip $\beta$ on motile microorganism density distribution when $N t=N b=E c=0.2, R=0.5, L b=\Omega=0.1, M=1, \xi=\gamma=\varphi=0.5, P e=0.2$, $L e=5$ and $P r=10$. 


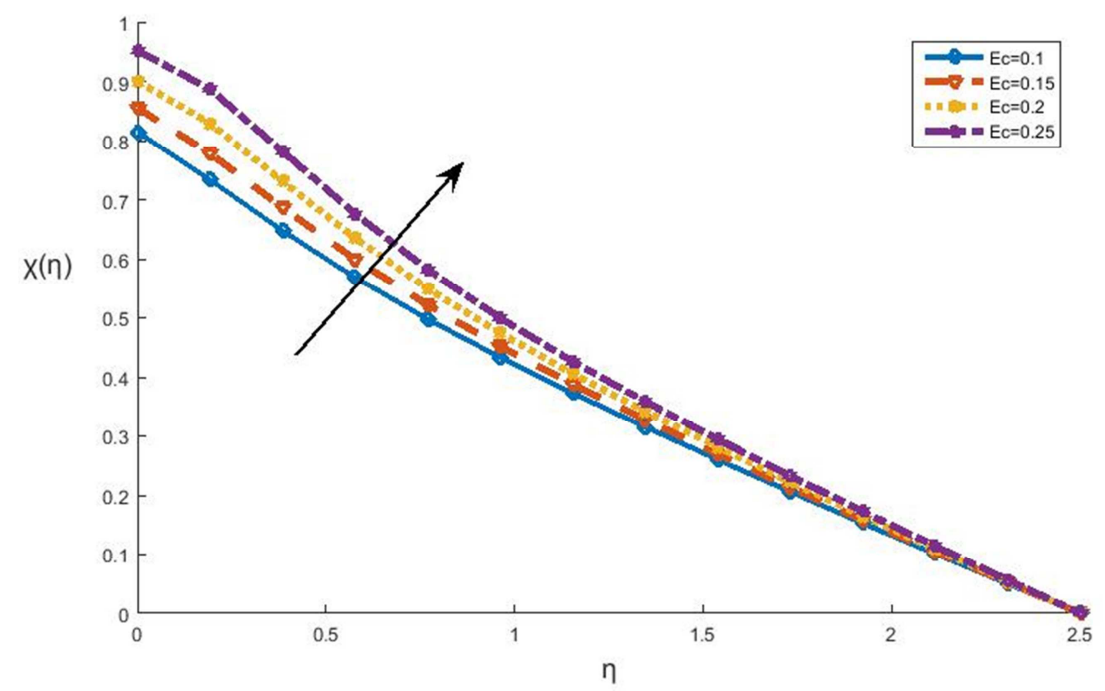

Figure 9. Effect of Eckert number Ec on motile microorganism density distribution when $N t=N b=E c=0.2, R=0.5, L b=\Omega=0.1, M=1, \xi=\gamma=\varphi=0.5, P e=0.2$, $L e=5$ and $\operatorname{Pr}=10$.

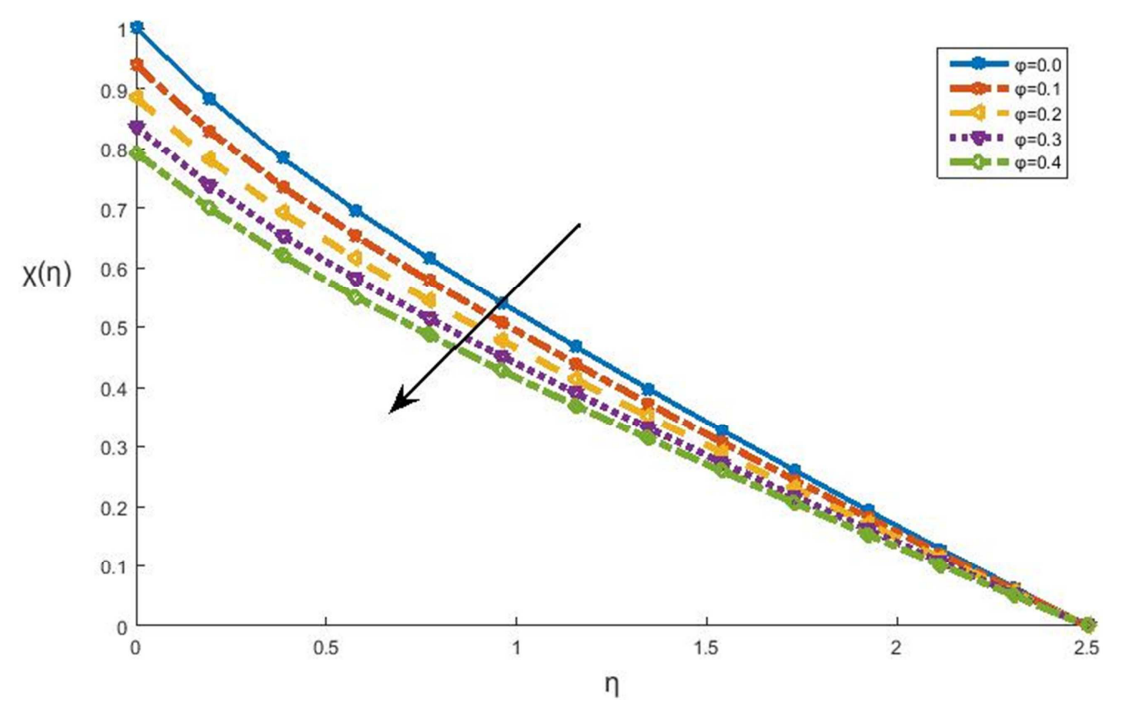

Figure 10. Effect of microorganism density slip $\varphi$ on motile microorganism density distribution when $N t=N b=E c=0.2, R=0.5, L b=\Omega=0.1, M=1, \xi=\beta=\varphi=$ $\gamma=0.5, P e=0.2, L e=5$ and $P r=10$.

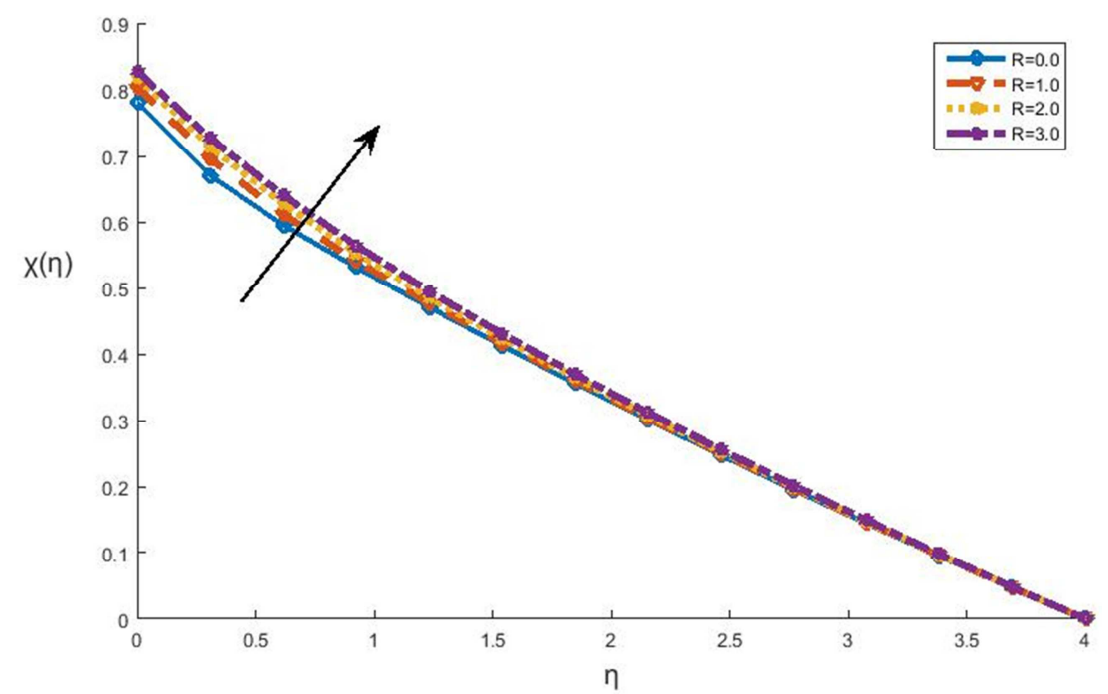

Figure 11. Effect of thermal radiation $R$ on motile microorganism density distribution when $N t=N b=E c=0.2, L b=\Omega=0.1, M=1, \xi=\beta=\varphi=\gamma=0.5, P e=0.2$, $L e=5$ and $P r=10$. 


\section{Conclusion}

In this present study, we have investigated the effect of Thermophoresis parameter, Eckert number, Prandlt number Brownian motion and slip parameters. The main findings of the study shows nanoparticle concentration decreases with increase Brownian motion $\mathrm{Nb}$ and Prandlt number Pr inside the boundary layer but increases with increase Nt. Also there is enhancement of the motile microorganism density profiles as thermal slip and Eckert number increase. Brownian motion $\mathrm{Nb}$ and Eckert number Ec decrease both local Nusselt number and local motile microorganism density but increases local Sherwood number. Thermophoresis parameter $\mathrm{Nt}$ suppresses both local Sherwood number, local Nuseselt number and local motile microorganism density.

\section{Nomenclature}

$\xi \quad$ Velocity slip parameter

$\beta \quad$ thermal slip parameter

$\gamma \quad$ concentration slip parameter

$\varphi \quad$ microorganism density slip parameter

$\mathrm{C}_{\mathrm{f}} \quad$ skin friction coefficient

$\mathrm{D}_{\mathrm{b}} \quad$ Brownian diffusion coefficient

$\mathrm{D}_{\mathrm{t}}$ thermophoresis diffusion coefficient

$\mathrm{f}$ dimensionless stream function

$\mathrm{K}$ thermal conductivity

Le Lewis number

$\mathrm{Lb}$ bioconvention Lewis number

Pe bioconvention péclet number

$\Omega \quad$ bioconvention concentration difference

M magnetic parameter

$\mathrm{Nb}$ Brownian motion parameter

$\mathrm{Nt}$ thermophoresis parameter

$\mathrm{Nu}_{\mathrm{x}} \quad$ local Nusselt number

$\mathrm{Nn}_{\mathrm{x}} \quad$ local motile microorganism density

Pr Prandtl number

$\mathrm{R}$ thermal radiation parameter

$\mathrm{Re}_{\mathrm{x}} \quad$ local Reynolds number

$\mathrm{T}$ temperature of the fluid inside the boundary layer

$\mathrm{Sh}_{\mathrm{x}} \quad$ local Sherwood number

$T_{w} \quad$ uniform temperature over the surface of the sheet

$\mathrm{T}_{\infty} \quad$ ambient temperature

$\mathrm{C}_{\mathrm{w}} \quad$ concentration

$\mathrm{C}_{\infty}$ ambient concentration

C nanoparticles concentration fraction

$\mathrm{u}, \mathrm{v} \quad$ velocity component along $\mathrm{x}$ - and $\mathrm{y}$-direction

$\mathrm{u}_{\mathrm{x}} \quad$ stretching velocity of the sheet

$\mathrm{B}_{0} \quad$ magnetic field strength

$\sigma^{*} \quad$ Stefan-Boltzmann constant

$\mathrm{K}^{*} \quad$ absorption coefficient

\section{Greek Symbols}

$\eta \quad$ dimensionless similarity variable

$\mu \quad$ dynamic viscosity of the fluid

$\sigma \quad$ electrical conductivity

$v \quad$ kinematic viscosity of the fluid ф dimensionless concentration function

$\chi \quad$ dimensionless number density of motile

microorganism

$\rho f \quad$ density of the fluid

$(\mathrm{c} \rho) \mathrm{f}$ heat capacity of the fluid

(c $\rho) \mathrm{p}$ effective heat capacity of a nanoparticle

$\psi \quad$ stream function

$\alpha \quad$ thermal diffusivity

$\theta$ dimensionless temperature

$\tau \quad$ parameter defined by $\frac{(\mathrm{c} \rho) \mathrm{f}}{(\mathrm{c} \rho) \mathrm{p}}$

\section{Subscripts}

$\infty \quad$ Condition at the free stream

$w \quad$ Condition at the surface

\section{References}

[1] M. H. Hamza, N. A. C. Sidik, T. L. Ken, R. Mamat, G. Najafi, Factors affecting the performance of hybrid nanofluids: a comprehensive review, Int. J. Heat Mass Transf. 115 (2017) 630-646.

[2] N. A. C. Siddik, M. J. Muhammad, M. A. A. J. Wan, M. A. Isa, A review on preparation methods, stability and applications of hybrid nanofluids, Renew. Sustain Energy Rev. 80 (2017) 1112-1122.

[3] O. D. Makinde, A. Aziz, Boundary layer flow of a nanofluid past a stretching sheet with a convective boundary condition, Int. J. Therm. Sci. 50 (2011) 1326-1332.

[4] S. Jana, A. S. Khojin, W. H. Zhong, Enhancement of fluid thermal conductivity by the addition of single and hybrid nano-additives, Thermochim. Acta 462 (2007) 45-55.

[5] Sreedevi P, Reddy, P. S and Chamkha, A. J: Magnetohydrodynamics Heat and Mass transfer analysis of single and mult-wall carbon nanotubes over vertical cone with convective boundary condition. Mech. Sci. 135, 646-655 (2018).

[6] Shafiq, A, Hammouch, A and Turah, A: Impact of radiation in a stagnation point flow of Walters' B fluid towards a Riga plate. Ther. Sci. Eng. 6, 27-33 (2018).

[7] Togun, H, Ahmadi, G, Abdulrazzaq, T, Shkarah, A. J., Kazi, S. N, A. Badarudin and M. R. Safaei, Thermal performance of nanofluid in ducts with double forward-facingsteps, Journal of the Taiwan Institute of Chemical Engineers, 47, 28-42, (2015).

[8] Uddin, M. J., O. Anwar Bég and A. I. Ismail, Radiativeconvective nanofluid flow past a stretching/shrinking sheet with slip effects, AIAA J. Thermophysics Heat Transfer, 29, 3, 513-523 (2015).

[9] Rana, P. and Bhargava, R. Flow and heat transfer over a nonlinearly stretching sheet: A numerical study. Comm. Nonl. Sci. and Numer. Simulat. 17, 212-226 (2012).

[10] Nadeem S, Mehmood R, Akbar N S., Non-orthogonal stagnation point flow of a nano non Newtonian fluid towards a stretching surface with heat transfer, Int. J. Heat Mass Transfer, 57: 679-689 (2013). 
[11] P. Rana, R. Bhargava, Numerical study of heat transfer enhancement in mixed convection flow along a vertical plate with heat source/sink utilizing nanofluids, Commun. Nonlinear Sci. Numer. Simul. 16 (11) (November 2011) 4318-4334.

[12] Sakiadis BC. Boundary layer behavior on continuous solid surface: II. The boundary layer on a continuous flat surface. J Am Ins Chem Eng 1961; 7 (2): 221-5.

[13] R. Nazar, N. Amin, I. Pop, Unsteady boundary layer flow due to a stretching surface in a rotating fluid, Mech. Res. Commun. 31 (1) (2004) 121-128.

[14] M. S. Abel, K. A. Kumar, R. Ravikumara, MHD flow, and heat transfer with effects of buoyancy, viscous and Joules dissipation over a nonlinear vertical stretching porous sheet with partial slip, Engineering 3 (3) (2011) 285-291.

[15] A. Y. Bakier, Thermophoresis effects on heat and mass transfer in MHD flow over a vertical stretching surface with radiation, Int. J. Fluid Mech. 36 (2010) 489-501.

[16] O. D. Makinde, W. A. Khan, Z. H. Khan, Buoyancy effects on MHD stagnation point flow and heat transfer of a nanofluid past a convectively heated stretching/shrinking sheet, Int. J. Heat Mass Transf. 62 (July 2013) 526-533.

[17] J. A. V. Kuznetsov, Thermo-bioconvection in a suspension of oxytactic bacteria, Int. Commun. Heat Mass Transfer 32 (2005) 991-999.
[18] Ibrahim W, Shanker B, Mahantesh M. MHD boundary layer flow and heat transfer of a nanofluid past a permeable stretching sheet with velocity, thermal and solutal slip Boundary conditions. Int J Heat Mass Transfer (2013); 75: 110.

[19] Andersson H. Slip flow past a stretching surface. Acta Mech 2002; 158: 121-5.

[20] Hayat T, Qasim M, Mesloub S. MHD flow and heat transfer over permeable stretching sheet with slip conditions. Int $\mathrm{J}$ Numer Meth Fluid (2011); 66: 963-75.

[21] Wang CY. Stagnation slip flow and heat transfer on a moving plate. Chem Eng Sci (2006); 61: 7668-72.

[22] Fang T, Zhang J, Yao S. Slip MHD viscous flow over a stretching sheet - an exact solution. Commun Non-linear Sci Numer Simul (2009); 14: 3731-7.

[23] Aziz A. Hydrodynamic and thermal slip flow boundary layer over a flat plate with constant heat flux boundary condition. Commun Non-linear Sci Numer Simul (2010); 15: 573-80.

[24] Fang T, Yao S, Zhang J, Aziz A. Viscous flow over a shrinking sheet with second order slip flow model. Commun Non-linear Sci Numer Simul (2010); 15: 1831-4. 